\title{
Degradation Process and Durability of Polymeric Materials for Architectural Applications
}

\author{
Silverio Hernández-Moreno \\ Mexico
}

\begin{abstract}
This review paper discusses the polymeric materials most commonly used in construction industry, where the main considerations and design recommendations for durability are reviewed. Besides, it aims to provide useful insights and information to professionals and researchers in areas related to construction and architectural materials to help them to make decisions when selecting materials from sustainable and durable design. The methodology was based on a review of scientific literature, where the main properties of polymeric materials were identified in the main considerations for the durable design of each polymeric material. We conclude that these materials consume large amounts of resources and energy in their process of manufacture, so, their use should be restricted. However, at the same time, they are durable and recyclable building materials with good operation and service life, especially serve as sealants, insulation, paints, pipes, window frames and exterior finishes.
\end{abstract}

Keywords: polymers, durability, service life, durable design, building materials

Published Date: March 2018

Published Online: $31^{\text {st }}$ March 2018

Corresponding Author: Silverio HernándezMoreno, silverhm2002@yahoo.com.mx

\section{Introduction}

Polymers are long molecular compounds, which largely can be organic and natural with a heavy molecular weight, however, they are very fine chemical substances and form small molecular compounds. These macro-molecules are formed by means of covalent bonds over a large number of repetitions of simple units, so the addition or subtraction of a little of these units does not change its properties ${ }^{[1]}$. Then, a polymer is a compound made of several parts or units, and this is called "polymerization" process.

Plastic is a sort of compound with low elasticity. If a deformation is applied and if such force is surpassed the deformation becomes irreversible. Elastomers are polymers with a high degree of elasticity and have a higher degree of tolerability against deformations than plastics. Because of this, plastic and polymers should not be used as synonyms. The general classification of polymeric materials is shown in Table 1 .

The application of each of these polymers will depend on the design requirements of the constructive components, climatic conditions, labor force, required maintenance and mainly both the intended final utilization and performance. For durability ends, thermostable polymers are the most durable followed by thermoplastics and elastomers. All these with the intention of reaching the requirements of the project, mainly in its phases of use, operation and maintenance with an approach of durability by design ${ }^{[4]}$.

The concept of durability is defined as the capacity that a building or a component reaches the optimal performance of its functions within a determinate environment for a certain amount of time with neither corrective maintenance nor significant reparations ${ }^{[5]}$.Thus, a durable design determines the service life of the infrastructure in the cities. Besides, it will also benefit the maintenance work of building components (Hernández-Moreno, 2015b).

On the other hand, polymers whether natural or artificial have become increasingly important as engineering materials ${ }^{[6]}$. Their range of properties and applications are at least as broad as that of other major classes of materials, and their ease of fabrication frequently makes them possible to produce finished items economically ${ }^{[6]}$.

The main uses of polymeric materials in the construction industry according to ${ }^{[7]}$ can be summarized as follows:

- Thermal insulation in walls and windows provides economic and environmental savings in terms of energy and comfort.

- Heat storage systems.

- Insulating and high durability windows.

- Passive use of solar energy.

- Polystyrene: in high-performance thermal insulation foams.

- Polypropylene: ventilation systems, energy control system, thermal insulation foam and solar Volume 2; Issue 2 
panels.

- Polyurethane: in the form of foams.

- Polyvinyl chloride: ventilation system, energy control system, window frames, solar panels.
- Polyethylene: ventilation system, floor heating.

- Polybutylene: floor heating.

- Engineering thermoplastics: ventilation system, fuel cells, energy control system and solar panels.

Table 1. General classification of polymeric materials

\begin{tabular}{|c|c|}
\hline Polymer class & Polymer sort \\
\hline $\begin{array}{l}\text { Thermoplastic materials (they can } \\
\text { be recast as many times as needed, } \\
\text { highly recyclable, their surface } \\
\text { accepts finishes with several related } \\
\text { materials, high impact resistance, re- } \\
\text { moldable, chemically resistant, but } \\
\text { they are more expensive than the } \\
\text { thermostable and are not resistant to } \\
\text { high temperatures.) }\end{array}$ & $\begin{array}{ll}\text { - } & \text { Polyethylene (PE) } \\
\text { - } & \text { Polypropylene (PP) } \\
\text { - } & \text { Polyvinylidene fluoride (PVDF) } \\
\text { - } & \text { Polyvinyl chloride (PVC) } \\
\text { - } & \text { Polystyrene } \\
\text { - } & \text { Polyamide / nylon (PA) } \\
\text { - } & \text { Ethylene tetrafluoroethylene (ETFE) } \\
\text { - } & \text { Polycarbonate (PC) (Figure 1) }\end{array}$ \\
\hline $\begin{array}{l}\text { Thermostable materials (they } \\
\text { cannot be recast, permanently in a } \\
\text { solid state, any extra amount of heat } \\
\text { or temperature would make them } \\
\text { burn or carbonize, they are most } \\
\text { commonly used as heat-resisting } \\
\text { materials, with good chemical and } \\
\text { mechanical resistance, mainly to } \\
\text { deformation. These materials can be } \\
\text { produced in thin sheets and have } \\
\text { better stability and durability and } \\
\text { inexpensive; however, they are not } \\
\text { recyclable and its surface does not } \\
\text { accept finishes easily.) }\end{array}$ & $\begin{array}{l}\text { Epoxies } \\
\text { - Phenolic } \\
\text { Polyesters }\end{array}$ \\
\hline $\begin{array}{l}\text { Elastomers (they are polymers with } \\
\text { high viscosity and elasticity } \\
\text { capacity, but the forces between } \\
\text { molecules are very weak. They } \\
\text { commonly have a low Young's } \\
\text { modulus.) }\end{array}$ & $\begin{array}{ll}\text { - } & \text { Butyl rubber } \\
\text { - } & \text { Polyurethane } \\
\text { - } & \text { Plasticized polyvinyl chloride } \\
\text { - } & \text { Silicone } \\
\text { - } & \text { Poly-chloroprene (Neoprene) } \\
\text { - } & \text { Poly-isoprene } \\
\text { - } & \text { Ethylene-propylene diene monomer (EPDM rubber) }\end{array}$ \\
\hline
\end{tabular}

(Source: ${ }^{[2,3,6,7,11,20,21]}$ ) 
Figure 1. Polycarbonate sheets for use in domes and "solariums" (photo: Silverio Hernández-Moreno, 2018).

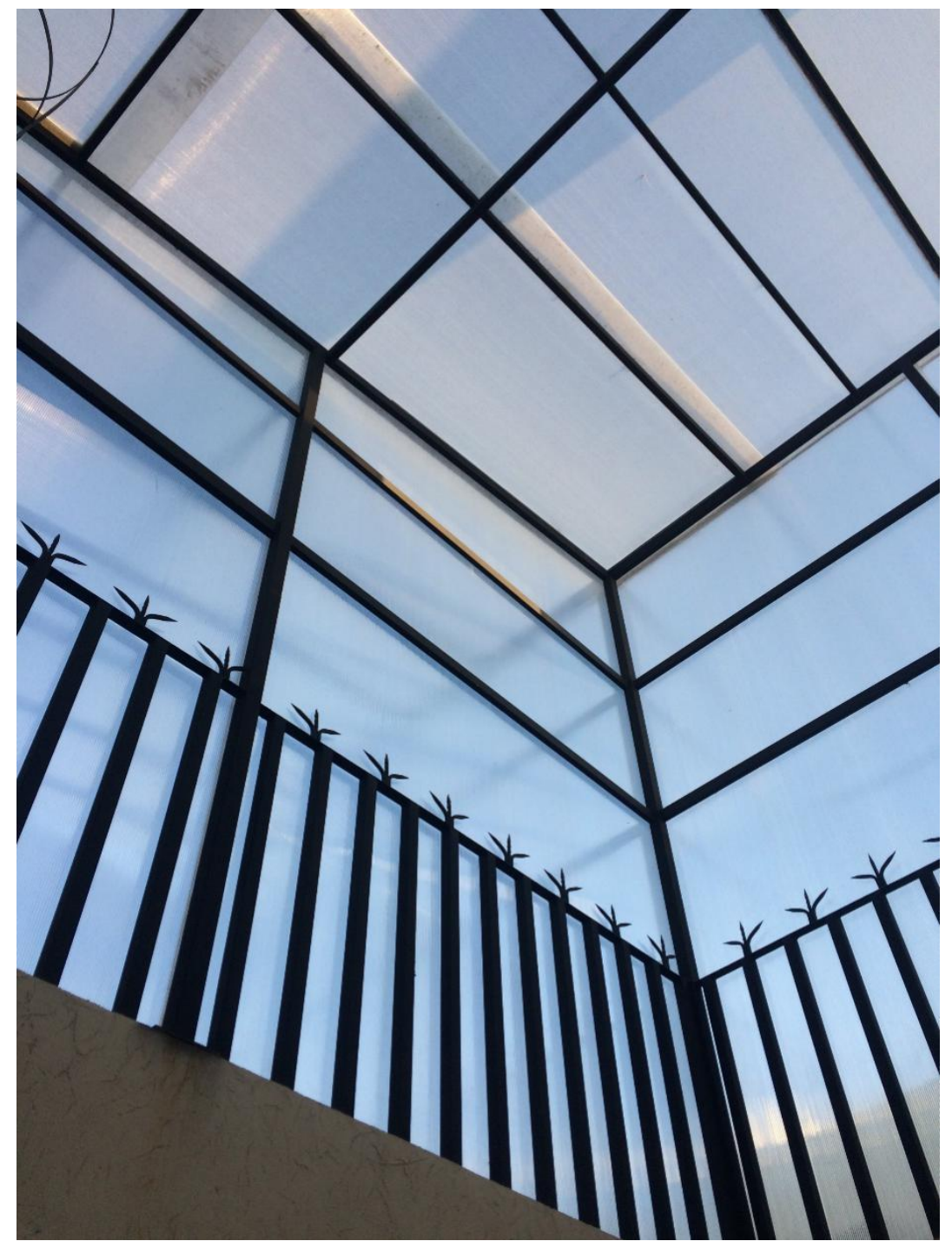

Another identified niche of the use of polymers in the construction industry is served as nano-structured materials like new photovoltaic cells, anticorrosive protector, sealant and insulator in electronics ${ }^{[8]}$. In another example, the use of nano-silica with particle diameters between $15-25 \mathrm{~nm}$ used to produce a superhydrophobic polymer matrix paint. It was found that the optimum performance was with a nano-silica concentration of $2-3 \%$ by weight of the matrix ${ }^{[9]}$.

Each material has different characteristics and applications, and for many cases, durability and the environmental aspect might be crucial factors in designing and building with these materials. From the environmental standpoint, the selection of polymeric materials is centered on biopolymers, which are materials of natural origin (such as natural rubber, collagen and polylactide materials) ${ }^{[10]}$. Although they are currently in research and development stage, they will be the major materials together with new cera- mics and glasses in the construction industry. For example, the polyurethane (PU) foams are one of the most widely used polymeric materials in the world ${ }^{[11]}$.

\section{Methodology}

(1) Briefly identify markets for the use of polymers in the construction industry (through literature review and manufacturers and suppliers data).

(2) Identify the main regulations for its application (through the revision of the current regulations in the matter).

(3) Identify the main properties of polymeric materials in the main considerations for durable design of each polymeric material. Divide these properties into mechanical, thermal, weathering and anticorrosion properties, permeability, pyro-resistance and environmental impact.

(4) Describe some key points of the durable design of the main (19) polymeric materials applicable to the 
construction industry and architecture to subsequently be able to select the appropriate materials for certain uses in construction through review of scientific literature from reliable sources.

(5) Determine its service life through a review of reliable scientific and technical literature of each of the polymeric materials with potential in the use in the construction and architecture industry.

(6) Classify the polymeric materials according to their useful life, their durability and their performance in the face of degradation and deterioration for the construction industry (according to the criteria of the architect and builder).

\section{Results}

\subsection{Brief description of the main markets for the use of polymers in the construction industry}

The commercial and industrial sector of construction was where the highest growth in the use and application of polymeric materials worldwide was identified. For its part, the residential sector came in third place in this area ${ }^{[6]}$. In larger scales, the use of polymeric materials has also been growing regularly in the transport sector ${ }^{[6]}$.

In general, the use of polymers in the construction industry has had a good acceptance because this type of materials is highly resistant to weathering and high durability ${ }^{[12]}$. For example, Fiber-Reinforced Polymer (FRP) is extensively used for repair and rehabilitation of concrete structures due to their excellent performance and ease of application ${ }^{[12]}$.

\subsection{Key regulations for its application}

The key considerations in which the production and use of polymeric materials have recently been legislated, lies in the environmental part of the products, even above the economic part, which is a good indication:

- Responsibility in the production and manufacturing processes under ecological schemes.

- Public health regarding the final disposal of its waste.

- Security in all stages of the life cycle of products and by-products made of polymeric materials.

2.3 Key points in the durable design of some constructive components made of polymeric materials

The following presents the key points in the durable design of some building components made of several polymeric materials from the point of view of the architect and builder.

Distributed under creative commons license 4.0

\subsubsection{Polyethylene (PET)}

Polyethylene is a thermoplastic polymeric material produced from ethylene. It is resistant, recyclable, inexpensive and durable. It is commonly used to make bottles, piping, insulation for electric conductors, impermeable membranes and tiles in roofs and foundations. The service life of these components, once built or installed as a system in the construction is expected to be of up to 80 years or more ${ }^{[13]}$ if they are well designed and receive adequate maintenance. In construction, their main use is act as a waterproof membrane in foundations and in the production of pipes for sanitary, water and electric installations. Waterproofing building roofs by means of polymeric membranes is a traditional system in construction; these are made of bituminous or asphaltic materials, which are polymers from oil plus diverse fine mineral aggregates, mainly sandstones and silica.

These granular materials of mineral origin are the main protection against degradation from structural dampness and mainly from ultraviolet radiation ${ }^{[14]}$. Polyethylene tiles are a very good option to protect roofs from structural dampness, as they are waterproof, fully impermeable, thermal-refracting, thornresistant and made of high-density polyethylene for a long service life. It is a thermoplastic and can be recycled easily and inexpensively.

On the other side, polyethylene membranes are also utilized for waterproof foundations, as it is a fast and inexpensive method to prevent dampness in concrete, footings, cementation slabs and similar components in close contact with dampness. Another important use of polyethylene is it can be used as a cable or electric conductor insulator.

The main considerations for a durable design with polyethylene are:

- Grade and thickness

- Number of layers

- Surface finish

- Adhesive for joints

- Preparation and placement

- Included accessories

- Resistance to corrosion

- Mechanical strengths of the material

- Tolerance to allow movements

- Adequate support and clamping

- Chemical resistance of sealants

- Exposition to UV radiation

- Dampness resistance

- Pollutant-free composition

- Thickness, density and resistance to tears

- Check constructive joints

Volume2; Issue 2 
- Block water and dampness from constrictive components

- Water penetration risk design

- Adequate in outdoor components exposed to rain and solar radiation

- Verify density, thickness, the integrity of joints, exposure to the environment, use as well as building height.

- Temperature changes in the roof system or slabs

- A prior brick and light mortar cover noticeably increases the durability of the roof slabs

- Tension, puncturing and shearing forces of the system

- Thickness and density of the roll

- Roll finish (upper membrane)

- Softening point

- Elongation at break

\subsubsection{Polystyrene}

A thermoplastic material derived from the polymerization of styrene. The service life of these components once built or installed as a system in the construction is expected to be 80 and up to 100 years ${ }^{[13]}$, if they are well designed, built and receive adequate maintenance.

It is commonly used for thermal and acoustic insulation and to make concrete slabs and roofs lighter. The sort of polystyrene most used in the construction industry is expanded and extruded polystyrene, which is lightweight with low density and thermal-acoustic insulators.

In addition, it is the $4^{\text {th }}$ most consumed plastic in the world behind polyethylene, polypropylene and PVC ${ }^{[15]}$. It is not an ecologic material because its fabrication (as with any polymer) leaves a high ecological footprint ${ }^{[16]}$, but it is very durable and with many characteristics and properties against deterioration and also has very good workability. The main considerations in durable design with polystyrene are:

- Type of polystyrene, which has to be expanded and/or extruded depending onthe intended use. Expanding it makes it lighter; it is mainly used in lightweight cubic blocks

- Good sealing to prevent dampness and filtrations

- Give continuity to the insulation system, in relation to the installation

- The material must be protected against impacts

- Considered it is a material with low mechanical strengths

- Extruded polystyrene is used as foam in walls and in "inverted waterproofing" in slabs and roofs

- Crystal polystyrene is used with other ends, for instance in CD's "jewel cases"; as it is hard and brittle

\subsubsection{Fiberglass}

These components' service life once built or installed as an insulation system is expected to be up to 80 years (depending on the application). For example, a water tank made of fiberglass can be used for 30-40 years ${ }^{[13]}$, if they are well designed, constructed and receive adequate maintenance.

It is the result of a glass mesh (lustered glass, of a few millimeters in size) with an epoxy resin, it is an insulating material, mechanically resistant depending on the mix design; it resists chemical attacks, it is malleable and resistant to traction and contractions. Fiberglass can be used as a material to shape boats, car parts, etc., but in the construction industry, it is largely used as thermal insulation, tank construction and fiberglass specialized fabrication for telecommunications. The main recommendations for a durable design with this material are:

For thermal insulation in roofs:

- Check there is no condensation risk

- Secure constructive joints and elements and sealed components to ensure insulation

- Material density

- Gauge of plates or sheets

- Integrity of the union between components

Ponds and water tanks:

- Sort of resin

- Thickness and density of the plastic

- Recycled content of the plastic

- Exposure to UV radiation

- Conditions of dust and dampness

- Sort of water to store

\subsubsection{Polyurethane}

This material represents a wide range of commercial products commonly classified as flexible, semi-rigid and rigid foams depending on the starting ingredients $[17,18]$.

The service life of these components once built or installed as a thermal insulation system in the shape of foam is expected to be 80 years and more while for piping, the estimated shelf life is ranging from 15 to 20 years ${ }^{[13]}$, if they are well designed, built and receive adequate maintenance.

Furthermore, it is a thermoplastic polymer (it can be cast again and go from solid to liquid as many times as needed, this is to say, it is recyclable) made from the condensation of hydroxylic bases combined with isocyanates and the "polymerization" of urethane. Polyurethanes are classified into two groups, which differ in chemical structure and temperature behavior. Following this way, there are two types of polyure-

Volume 2; Issue 2 
thanes, either thermostable or thermoplastic. It can be synthesized as foam, thermoplastic, and even as an elastomer, fiber, resin, adhesive or sealant. Owing to its good resistance to abrasion and external chemical attacks (acids, $\mathrm{CO}_{2}$, dampness, dust, etc.), it has many applications in construction, including thermal insulator as foam in addition to other acoustic characteristics, glue and sealant, etc. Comparatively, thermoplastic polyurethane, most of the times is used as an adhesive as it is very compatible with many polymers, for examples, PCV, rubber, polystyrene and polyethylene.

The durability of polyurethane can be characterized with accelerated aging tests, corresponding to American norm AS2282.

\subsubsection{Adhesives, paints and plastic sealants}

The service life of these components once built or installed as a system is expected to be from 3 to 7 years depending on their quality ${ }^{[13]}$ if they are well designed, built and receive adequate maintenance.

We have the following points of durable design for components made of or combined with polyurethanes, silicon, epoxy, etc.

\subsubsection{Polyurethane}

- In paints, sealants and finishes, due to the imperfection of the surface and contraction damages especial attention should be paid to the preparation of the surface.

- Water penetration risk design

- Adequate in outdoor components exposed to rain and solar radiation

- Check the density, thickness, integrity of unions, exposition to the environment and the use and height of the building.

- Number of paint coats

- Surface finish (check if it is ceramic, wood or metal)

- Adhesive for unions

- Preparation and installation

- Tolerance to allow movements

- Mechanical strengths of the constructive elements

- Adequate support and fastening

- Chemical resistance of sealants

- Exposition to UV radiation

- Repaint (determine the frequency and maintenance based on the quality of the product and the conditions of climate and installation)

- Quality, grade, gauge, mechanical strengths of the material.

- Unions, welding, sealing and overlapping (figure 2)
Figure 2. Windows and doors sealing (photo: Silverio Hernández Moreno, 2018).

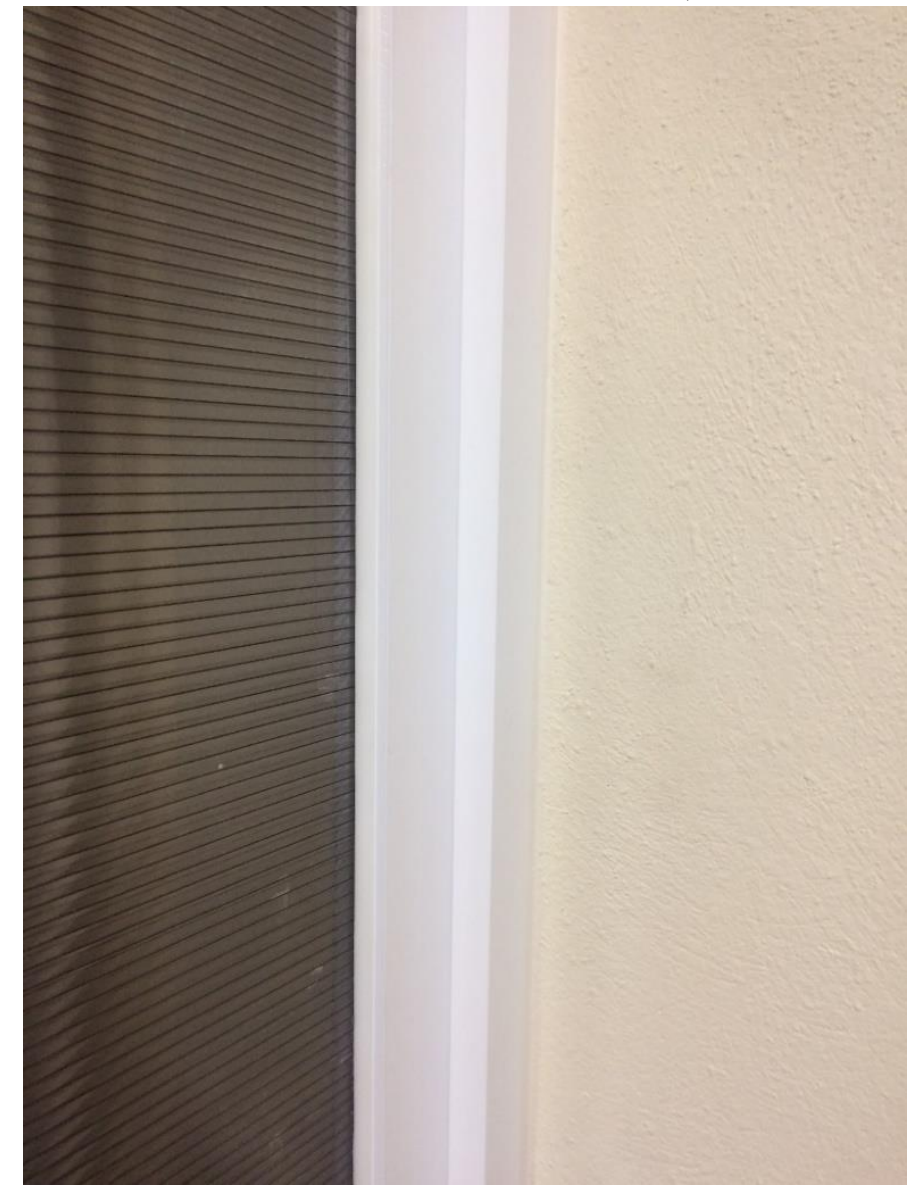

- Paints and sealants accelerated aging: ISO 2810 and AS 1580

- Use of materials with low emission of volatile substances (avoid the use of sealants and paints with a high content of VOC).

- Sort and number of layers of the definitive finish, such as paints, varnishes or sealants

The characterization and accelerated aging test for this material will be corresponding to $A S 2282$ and ISO 2810 and $A S 1580$.

\subsubsection{Silicone}

Silicon is an inorganic elastomer polymer derived from the polymerization of polysiloxane. It is composed of silicon and oxygen atoms with uses in construction, such as adhesive and paints in most of the cases.

The points on durable design for silicone products are the same as the previous entry, but with different characterizations and tests.

- In paints, sealants and finishes, because of the surface imperfections and contraction damage especial attention shall be paid to prepare the surface.

- Water penetration risk design

- Adequate in outdoor elements exposed to rain and 
solar radiation

- Check the density, thickness, integrity of unions, exposition to the environment and the use and height of the building.

- Number of paint coats

- Surface finish (check if it is ceramic, wood or metal)

- Adhesive for unions

- Preparation and installation

- Tolerance to resist movements

- Mechanical strengths of the constructive elements

- Adequate support and fastening

- Chemical resistance of sealants

- Exposition to UV radiation

- Repaint (determine the frequency and maintenance based on the quality of the product and the conditions of climate and installation)

- Quality, grade, gauge, mechanical strengths of the material.

- Unions, welding, sealing and overlapping

- Paints and sealants, accelerated aging: ISO 2810 and AS 1580

- Use of materials with low emission of volatile substances (avoid the use of sealants and paints with a high content of VOC).

- Sort and number of layers of the definitive finish, such as paints, varnishes or sealants

The characterization and assessment of these materials' durability in combination with biodegradable raw materials such as natural rubber can be revised in ${ }^{[19]}$.

\subsubsection{Epoxy}

It is a material polymerized from polyamines, polyamides, polysulfides, urea, phenol formaldehyde and acids or anhydrides by addition or condensation [20].

A thermostable polymer (it can neither be recast nor recycled) with the property of solidifying in short time and with high adherence and viscosity to any sort of material: other polymers, metal, glass, woods, etc.; it is produced in various presentations for different applications such as: pure (high protection against corrosion and abrasion); modified (especially to protect structural steel and pipes); phenolic (coatings for ponds and steel tanks which hold hightemperature liquids); rich in zinc (as primer or first coating in aggressive environments and where corrosion is the main degradation factor of the materials to be protected); with aluminum (clear and resistant to sea salts, industrial chemicals and radiation deterioration); with iron oxide (anticorrosive coating, flexible and waterproof); with fiberglass (anticorrosive coating with high resistance to abrasion and impact, which allows thicker finish layers); as pitch (long-lasting steel protection and other structural materials in very corrosion environments; resistant to gas-oil, fuel-oil and crude oil, etc.). The main points for durable design to pay attention to include:

- In paints, sealants and finishes because of surface imperfections and material contraction damage especial care shall be taken to prepare the surface

- Water penetration risk design

- Adequate in outdoor elements exposed to rain and solar radiation

- Check the density, thickness, integrity of unions, exposition to the environment and the use and height of the building.

- Number of paint coats

- Surface finish (check if it is ceramic, wood or metal)

- Adhesive for unions

- Preparation and installation

- Tolerance to resist movements

- Mechanical strengths of the constructive elements

- Adequate support and fastening

- Chemical resistance of sealants

- Exposition to UV radiation

- Repaint (determine the frequency and maintenance based on the quality of the product and the conditions of climate and installation)

- Quality, grade, gauge, mechanical strengths of the material.

- Unions, welding, sealing and overlapping

- Paints and sealants, accelerated aging: ISO 2810 and AS 1580

- Use of materials with low emission of volatile substances (avoid the use of sealants and paints with a high content of VOC).

- Sort and number of layers of the definitive finish, such as paints, varnishes or sealants

\subsubsection{Alkyd resins}

Alkyd resins are based on a combination and reaction of acids, alcohols and oils. A large number of synthetic resins can be produced, which are called alkyd and whose main uses are the production of paints and varnishes; synthetic solvents are used to apply them. As for durability, they are very resistant, however, their ecological footprint is very high.

\subsubsection{Acrylic resins}

Resins based on acrylic acid produced from propylene or propane, which are alkenes, the base for acrylic resins, to mainly produce paints and varnishes; synthetic solvents are used in their application. As for

Volume 2; Issue 2 
durability, they are very resistant, however, their ecological footprint is very high.

\subsubsection{Vinyl resin}

The organic polymer produced by means of polymerizing hydrocarbons, mainly vinyl chloride. Water is used as a solvent, more ecological than the two previous resins, but less durable.

\subsubsection{Polyvinyl chloride (PVC) (pipelines, floors,} doors and windows)

$\mathrm{PVC}$ is a thermoplastic polymer (that can be recycled by means of recasting processes, ${ }^{[21]}$. It is the product of polymerization of vinyl chloride monomer. In the construction industry, PVC is classified into two categories: rigid and flexible. In its pure form, PVC is a rigid material while it became flexible with the addition of additives, so that it can be used in pipes (Figure 3), sheets for roofs, windows, doors, blinds, tiles, conductor and cable insulation and even shoe soles, bottles and other applications.

Figure 3. PVC used in pipes (photo: Silverio Hernández-Moreno, 2018).

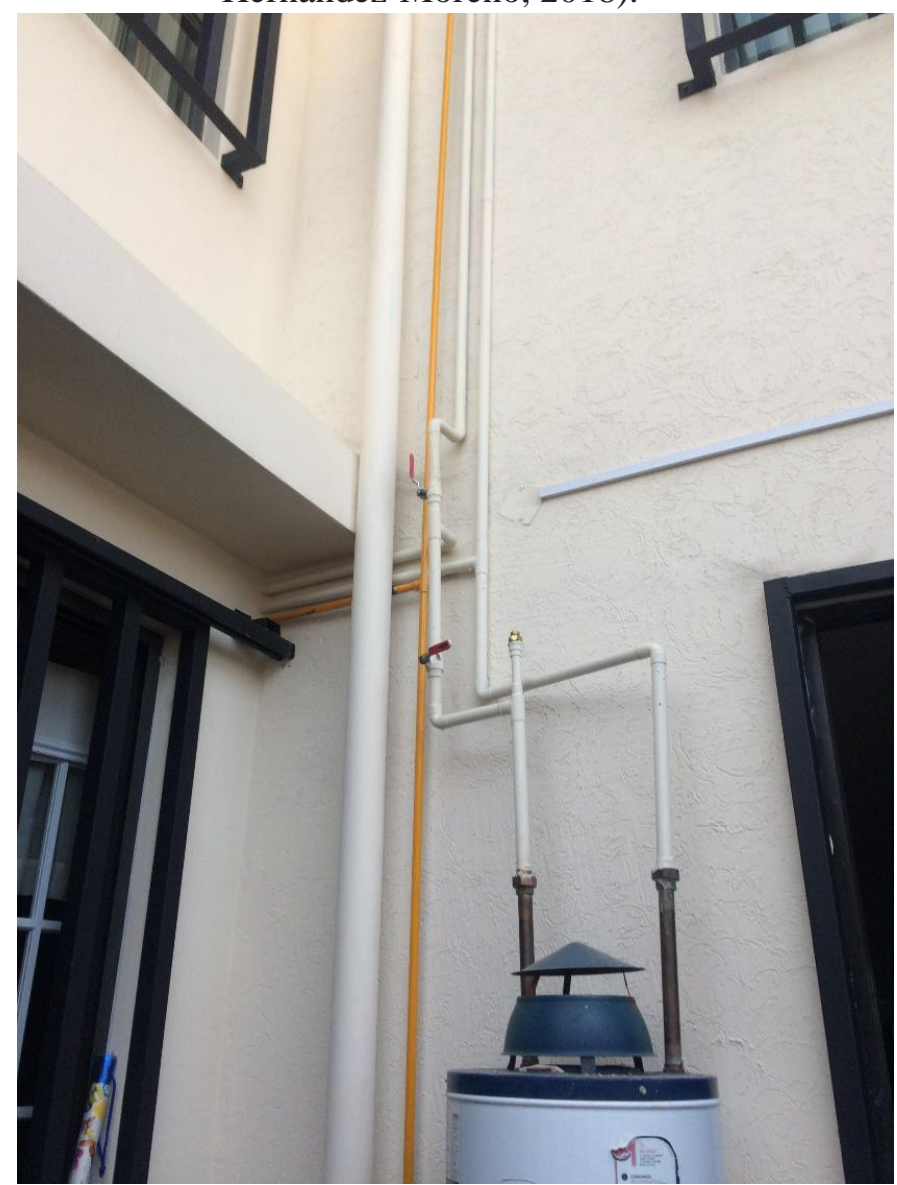

The service life of these components once constructed or installed as a system for pipelines is expected to be up to 80 years, and for floors and windows can up to 50 years ${ }^{[13]}$, if they are well designed, built and receive adequate maintenance.

As with all polymers, $\mathrm{PVC}$ is a material with a heavy environmental impact in its manufacture, but once installed it is durable and easy to maintain, thereby in the processes of design and sustainable construction [22], selecting a PVC component will have to be validated on the basis of the pros (durability and versatility) and cons (the high ecological footprint). Hence, it should only be used if it is in high demand. However, it is recommendable to use in pipelines and accessories for water and sanitation installations because of its excellent performance, functionality and durability.

Points related to the durable design of constructive elements made of this material:

\subsubsection{Flexible PVC for tiles}

- The type and grade of PVC shall be selected according to the intensity of use and localization. There are up to $10 \mathrm{PVC}$ grades according to use, either domestic or industrial

- Appropriate tile thickness

- Appropriate thickness of the tile finish

- The sub-base shall be smooth, firm and dust-free

- Appropriate conditions of the sub-base, in this case, a firm floor made of mortar smoothened with sand and cement shall be free from dampness by means of a protective membrane

- Use the adhesive specified by the manufacturer

- Regular mopping and polishing

- Excessive use of water for everyday cleaning should be avoided

- Colored rigid PVC for windows and doors

- Gauge

- Resistance to corrosion and dampness

- Conditions of use and location

- Adequate support and fastening

- Provision for dampness and temperature-related movements

- Check slots for dripping and the slope of the base

- Additional physical protection against weather and solar radiation for eave covers, façade blinds or the creation of micro-climates with trees and vegetation

- Cleaning of the parts

- Cleaning and lubrication of the parts

- Adjust screws and bolts

\subsubsection{PVC for pipelines}

- Grade and gauge of plastics

- Number of layers

- Surface finish

- Adhesive for unions

- Preparation and laying

- Mechanical accessories

- Resistance to corrosion

Volume2; Issue 2 
- Mechanical strengths of the pipeline material

- Tolerance to allow movements

- Adequate support and fastening

- Chemical resistance to sealants

- Exposition to UV radiation

2.3.15 Flexible PVC for electric conductor insulation

- Type, grade and transversal area of the cable

- Type and grade of the metallic conductor

- Protection against bugs, rodents, solvents and aggressive chemicals

- Extra protection against mechanical damage by means of an electrical conduit

- Operation temperature (both low and high temperatures can be harmful)

\subsubsection{PVC for water tanks}

- Sort of plastic

- Thickness and density of the plastic

- Content of recycled plastic

- Exposition to UV radiation

- Conditions of dust and dampness

- Sort of water to store

\subsubsection{Polypropylene (floors, roof tiles)}

The service life of these components once constructed and installed as a system in the construction of sanitary piping is expected to be up to 30 years or more, and for roofs and covers could up to 40 years depending on the solar radiation incidence and dampness conditions ${ }^{[13]}$, if they are well designed, built and receive adequate maintenance.

Polypropylene (PP) is a thermoplastic polymer (that can be recast and recycled ${ }^{[23]}$. It is the product of polymerizing propylene or propane. In general, PP has many applications in industry, mainly as packaging (boxes, buckets and containers). In the textile industry, it is used in fibers and strings, and recently as thermal insulation, carpet fabrication, artificial turf, moldings and cornices and mainly prefab modules, such as booths, containers and 1-story houses in the construction industry.

One of its most important characteristics is its resistance to chemical solvents, acids and bases mainly; high resistance to abrasion, flexion and fatigue and impact. As any other polymer, its ecological footprint is high in its manufacture, however, once installed it is versatile, durable and inexpensive. The main durable design points to consider are:

- Check adherence

- Check joints

- Vent the roof system

- Mitigate solar radiation
- Material thickness

- Resistance to tears

- Impermeable properties

- Continuity in its installation

- Replacement of parts due to bad installation

\subsubsection{Polymer-modified asphalts}

The service life of these components once built or installed as a system is expected to be 5 and up to 10 years ${ }^{[13]}$, if they are well designed, built and receive adequate maintenance.

Asphalt is a hydrocarbon derivative that can be obtained in two ways. In the first way, it is the most common and inexpensive, and collected as a byproduct of crude oil refining. In the second, it is obtained from large natural deposits as bitumen. On the other side, asphalt is a material used as agglutinant in roads and pavements mixed with pea gravel and other aggregates (producing asphalt "concrete"), which make it a very economical material for roof waterproofing and foundations.

In its simple form, it is not so resistant to repeated compression and tension stress, neither is it resistant to extreme temperatures nor fatigue. In order to improve all these properties polymeric modifiers are added, namely: monomers, copolymers and elastomers to increase its resistance to compression and tension deformations, noticeably reducing fissures and cracks ${ }^{[24]}$ mainly on pavements made of this sort of asphalt (modified asphalt).

Recommendations for durable design:

- Modify the bitumen or asphalt with polymers to make it more resistant to tension and contraction.

- Limit its use in buildings, since its ecological footprint is high.

- Combine asphalt with inert clean aggregates to prevent contamination in the mixes so that it is more durable and resistant as well.

- For pavements, it is recommended that the asphalt surface is porous to prevent slips in wet surfaces using basaltic rock aggregates in the mixes, and at the same time maintaining low permeability ${ }^{[25]}$.

\section{Conclusion}

All polymers are synthetic materials that require large amounts of resources and energy to produce, thereby they are materials with high ecological footprint and from the strictly environmental standpoint, their use should be restricted. On the other side, they are widely used in the construction industry all over the world, mainly as sealants, glues and paints attributed to their long service life and excellent durability.

It is recommended to select polymeric materials with

Volume 2; Issue 2 
a biopolymeric origin and thermoplastic process. In this way, their environmental impacts will be reduced, as their materials are biodegradable and recyclable.

There are also nano-polymers that have various applications in the construction industry, such as structural, thermal, weathering, pyro-resistant materials, in construction finishes, hydrophobic, among other applications.

In terms of environmental impacts, it is sought that throughout the life cycle of this type of materials are achieved reduce $\mathrm{CO} 2 \mathrm{eq}$ emissions, during manufacturing and use processes, and also other toxic emissions, that in polymers are very common, such as Volatile Organic Compounds (VOC), Chemical carcinogens and endocrine disruptors, toluene, benzene and xylene, etc., among other substances more that can damage public health and ecosystems but have an adequate treatment.

\section{References:}

[1] Wagner Jr. John R., Mount III Eldridge M, Giles Jr. Harold F. (2014). "Polymer Overview and Definitions" in (Editores: M. Bauser, G. Sauer, and K. Siegert) Extrusion (Second Edition), ASM INTERNATIONAL, USA.

[2] Fernandez John E. (2014). "Lecture I: Performance, Properties and Selection", course: Emergent Materials Workshop the Ecology of Construction Materials, Department of Architecture. MIT. USA.

[3] Modor (2015). Catálogo de productos plásticos Modor. A division of Kanson Electronics Inc. (revised and retrieved from:

www.modorplastics.com).

[4] Hernández-Moreno, Silverio; Servín-Cárdenas, Paula; Ocampo-Lugo, Dulce Guadalupe. (2017). Comparative analysis method for service life estimation in architectural and durable design, Entreciencias: diálogos en la Sociedad del Conocimiento, vol. 5, no. 12.

http://www.redalyc.org/articulo.oa?id= 457650040008

[5] CSA [Canadian Standards Association]. (2001). S478-95 (R2001), Guideline on Durability in Buildings, pp. 9-17, Ottawa, Canada: CSA.

[6] Halliwell S.M. (2003). Polymers in Building and Construction, Rapra Technology Limited, United Kingdom.

[7] Correia Diogo A. (2015) Polymers in Building and Construction. In: Gonçalves M., Margarido F. (eds) Materials for Construction and Civil Engineering. Springer, Cham

[8] Hernández-Moreno, Silverio and Solache de la

Distributed under creative commons license 4.0
Torre, Sara Cristina (2017). Nano--technological products in architecture and construction, HOLOS, 33 (22), pp. 35-51. DOI: 10.15628/holos. 2017.5497

[9] Karmouch, R. and G. G. Ross. (2010). Superhydrophobic wind turbine blade surfaces obtained by a simple deposition of silica nanoparticles embedded in epoxy, Appl Surf Sci, 257 (3): 665669.

[10] Chumekaa Wannapa, Pasetto Pamela, Pilard Jean-François, Tanrattanakul Varaporn. (2014). Biobased triblock copolymers from natural rubber and poly (lactic acid): Synthesis and application in polymer blending, Polymer, 55 (17), pp. 4478-4487.

[11] Oertel G. (1993), Polyurethane Foams, Hanser Publishing, Munich, Germany.

[12] Fen-tao Liu, Guo-hui He, Jun-hua Xiong (2017). Experimental study on durability of FRP sheets under wet-dry cycles in various solutions, Procedia Engineering, 210 (2017), pp. 61-70.

https://doi.org/10.1016/j.proeng.2017.11.049

[13] Hernández-Moreno, Silverio (2015a). Diseño por durabilidad en arquitectura y edificación, editorial Trillas, México.

[14] Marques J.A., Lopes J.G., Correia J.R. (2011). Durability of the adhesion between bituminous coatings and self-protection mineral granules of waterproofing membranes, Construction and Building Materials, 25 (2011), pp. 138-144.

[15] Chunming Wang, Lei Dong. (2015). Exploring 'new' bioactivities of polymers at the nano-bio interface, Trends in Biotechnology, 33 (1), pp. 10-14.

[16] Höfer R. and Selig M. (2012). "10.02 - Green Chemistry and Green Polymer Chemistry", en Polymer Science: A Comprehensive Reference, pp. 10-14, ELSEVIER, USA.

[17] Ligoure C., Cloitre M., Le Chatelier C., Monti F., Leibler L. (2005). Making polyurethane foams from microemulsions, Polymer 46 (2005), pp. 6402-6410.

[18] Randall D., Lee S. (2002). The Polyurethanes Book, Wiley, New York, 2002.

[19] Virlogeux Fabien, Bianchini David, Delor-Jestin Florence, Baba Mohamed, Lacoste Jacques. (2004). Evaluation of cross-linking after accelerated photoageing of silicone rubber, Polymer International, 53 (2), pp. 163-168.

[20] Billmeyer Fred W. (2004). Texto de la Ciencia de los Polímeros; (Reimpresión). Editorial REVERTÉ, Barcelona, Spain.

[21] Sadat-Shojai Mehdi, Bakhshandeh Gholam-Reza. (2011). Recycling of PVC wastes, Polymer Degradation and Stability, 99 (4), pp. 404-415.

[22] Stichnothe Heinz, Azapagic Adisa. (2013). Life Volume2; Issue 2 
cycle assessment of recycling PVC window frames, Resources, Conservation and Recycling, 71 (2013), pp. 40-47.

[23] Pacheco Filho José Geraldo A., Cruz Graciliano Emerson, Osimar S. Silva Antonio, Souza Marcelo J.B., Souza Araujo Antonio. (2005). Thermo gravimetric kinetics of polypropylene degradation on ZSM-12 and ZSM-5 catalysts, Catalysis Today, 107108 (2005), pp. 507-512.

[24] Soltani Mehrtash, Moghaddam Taher Baghaee,
Rehan Karim Mohamed, Shamshirband Shahaboddin, Sudheer Ch. (2015). Stiffness performance of polyethylene terephthalate modified asphalt mixtures estimation using support vector machine-firefly algorithm, Measurement, 63 (2015), pp. 232-239.

[25] Frigio F., Pasquini E., Ferrotti G., Canestrari F. (2013). Improved durability of recycled porous asphalt, Construction and Building Materials, 48 (2013), pp. 755-763. 